\title{
A Comparison of the Biology of Echinus esculentus in Different Habitats. Part II.
}

\author{
By
}

Hilary B. Moore, Ph.D.,

Marine Biological Laboratory, Plymouth.

With 10 Figures in the Text.

Echinus esculentus has been studied from the "Breakwater" ground on the side of the ruined breakwater in Port Erin Bay, from a depth of about one metre up to low water of ordinary spring tides, also from the " Breast " ground off Port Erin in 25 to 35 metres, and from the " Chickens " ground further offshore in 60 to 70 metres. An account of the seasonal changes in the urchin gonads from these grounds was given in a previous paper (Moore, 1934), where the grounds are described in fuller detail. Further samples were trawled on a sandy bottom in "Niarbyl" Bay near Port Erin in about 7 metres, and also, through the courtesy of Mr. R. Elmhirst, off Keppel Pier in the Clyde in about 9 metres.

\section{Methods.}

The method of collecting varies of necessity on the different grounds, and was in some cases selective with regard to size of urchin captured. On the Breakwater the samples were collected by hand, and a fair sample of the population was obtained. Some of the Breast samples were dredged, which yielded small but representative samples, while others were taken with an otter trawl which was liable to miss the smallest sizes. The two methods combined gave plenty of large and small urchins, but rather small numbers of intermediate sizes. The Keppel and Niarbyl samples were collected with otter trawls, and were deficient in the smallest sizes. The Chickens urchins were obtained from pots set by local fishermen for Buccinum undatum. Very small specimens were liable to be washed out of the pots during hauling if the weather was stormy, especially in winter. They were also apt to be overlooked by the fishermen. On the whole, however, the Chickens sample was representative.

Diameter and Height were measured with sliding calipers which were read to the nearest millimetre. The caliper ends were pointed for reading diameters, while for heights, one end was fitted with a knife-edge to span the peristome. 
External volume was measured by displacement of water from a vessel fitted with an overflow pipe, or, in the case of dried shell, by displacement of lead shot from a vessel of known volume, and the results obtained were accurate within about $\pm 2 \%$. Volume alive was measured in the same way. Internal volume was measured by filling the dried shell with lead shot, or, in the case of very small specimens, with mercury. The internal volume is related to the volume alive, with spines, by the formula $V_{a}=1 \cdot 28 \times V_{i}$.

\section{LOCAL VARIATION.}

One characteristic distinguishing the Breakwater from the Breast race has already been described, namely, the difference in volumes of their gonads, which, when full, reach nearly five times the size on the Breakwater that they do on the Breast. Those from the Chickens agree in this particular with the Breast (Moore, 1934). It appears that this difference is correlated with the amount of food available on the different grounds.

The difference in the growth rates of the urchins is discussed later. A further difference lies in the colour of the test. On the Breakwater this varies more or less uniformly between violet or mauve and red or yellowish. On the Breast the violet or mauve type is much rarer, although a few such specimens are to be found, while on the Chickens only a single mauve specimen was found among about a thousand urchins examined, the rest all being red. This test colouration must be distinguished from that of the spines which does not necessarily agree with that of the test, and appears to be due to an entirely different pigment. It is hoped in a later paper to discuss the nature of these pigments in more detail.

For a study of the local differences in test structure, samples of 150 to 170 urchins were taken from each of the three grounds, Breakwater, Breast and Chickens, and the following measurements made on each specimen - test diameter, test height, polar circumference, internal volume, external volume and test thickness. The latter was measured on the cut edge of one of the large interambulacral plates, which were found to give consistent results for any one specimen. It was hoped that polar circumference would prove to be a good measure of the size of the animal, not seriously varying with the shape of the urchin, but this was found not to be the case. In practice, therefore, either the internal volume of the test or its cube root was taken as the best measure of the size of the animal. Owing to the change in shape during the life of the urchin, and also to the racial differences in shape referred to below, diameter is not a very satisfactory measure of size, and is avoided wherever possible.*

The data for the shell thickness are shown in Figure 1, plotted against cube root of volume. The increase of thickness is not quite linear throughout life, the older animals being relatively slightly thinner shelled. The

\footnotetext{
* Conversion tables for diameter-volume are given in Table I.
} 
Breast and Chickens races agree substantially, but differ from the Breakwater race in being about twenty per cent thinner. This difference is so marked that the local fishermen consider them to be two different kinds of urchin.

Figure 2 shows the variations in shape on the three grounds, together with the Niarbyl sample. There is a steady increase in relative height

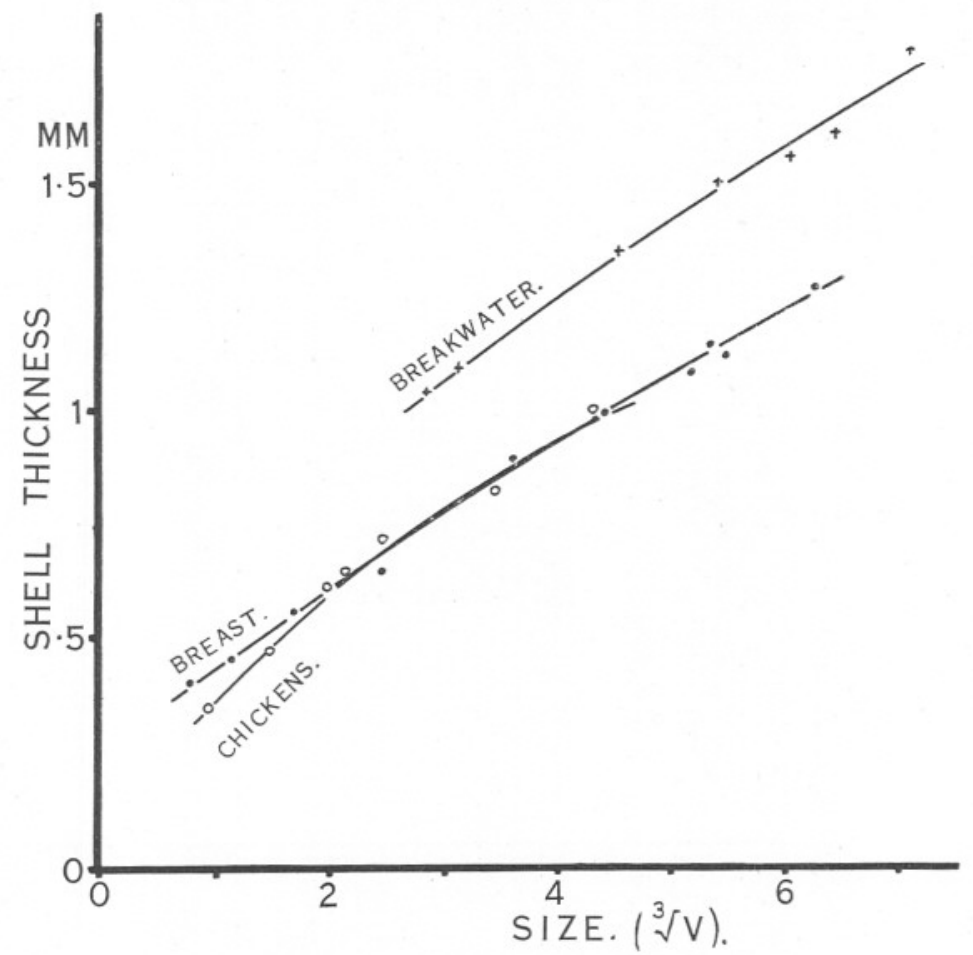

Fig. 1.-Relation of shell thickness to size.

throughout life on all grounds, but tending to become more or less constant in the largest individuals. The Breakwater, Breast and Chickens races differ slightly among themselves, but all range from a value of height

$\overline{\text { diameter }}$ of about 0.5 when very small to about 0.7 when adult. The

Niarbyl sample was strikingly tall throughout. Such very tall races are known to occur locally elsewhere. Elmhirst states (personal communication) that they occur on the Skelmorlie Bank in the Clyde, in about 12 metres.

D'Arcy Thompson (1917, p. 661 et seq.), in discussing the shape of urchins, shows that the downward and outward pull of the tube-feet will 
tend to flatten the shell unless it grows thicker to resist this pull. The urchins from the Breakwater, being in a zone in which they are exposed to wave action, will have to exercise a greater pull with their tube-feet in order to resist dislodgment, than will similar urchins from the comparatively quiet waters of the Breast or Chickens grounds. Theoretically, therefore, the Breakwater urchins should either be flatter or else thicker shelled than those from the off-shore grounds, and in practice they are found to be both thicker and flatter. This seems to present at least a

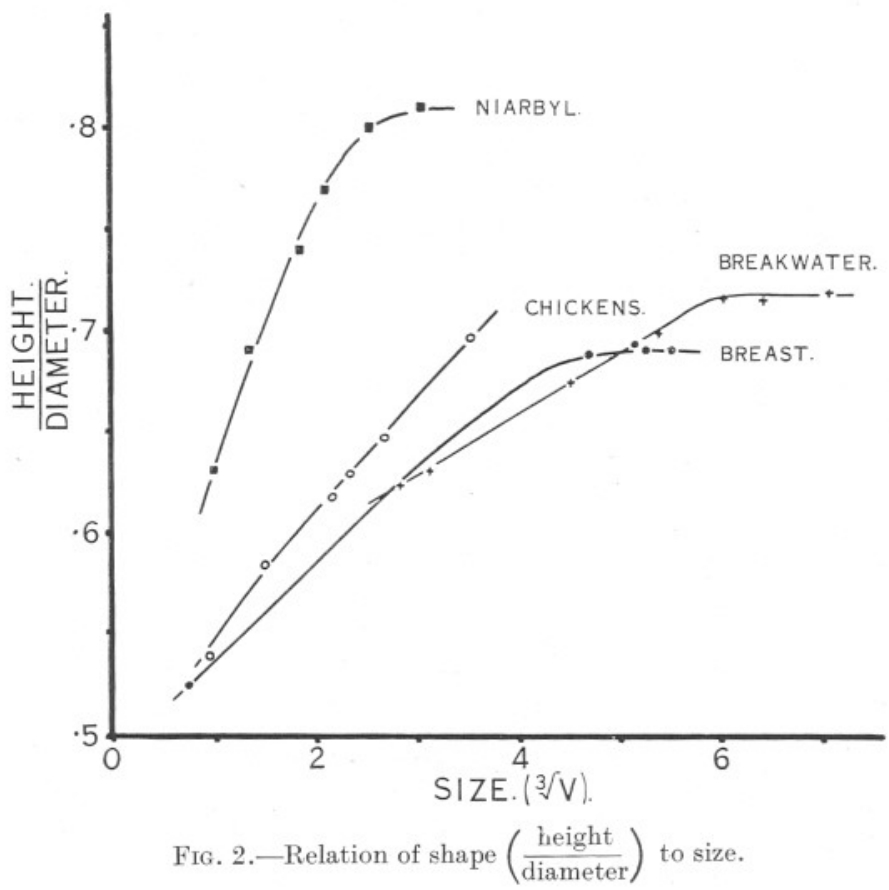

partial explanation of the differences, although diet probably plays a part also in determining thickness of shell, and the changes with age still remain to be explained.

\section{Size Distribution.}

The Chickens ground, although atypical in the small growth rate found there, yields the simplest size data. The sampling on it is representative, and there is little likelihood of immigration of urchins from elsewhere on to this deep-water ground since it is bounded on the outside by a deeper area with unsuitable mud bottom. And the only known case of migration is in a shorewards direction on to the Breakwater.

About nine hundred Chickens urchins were measured, comprising 


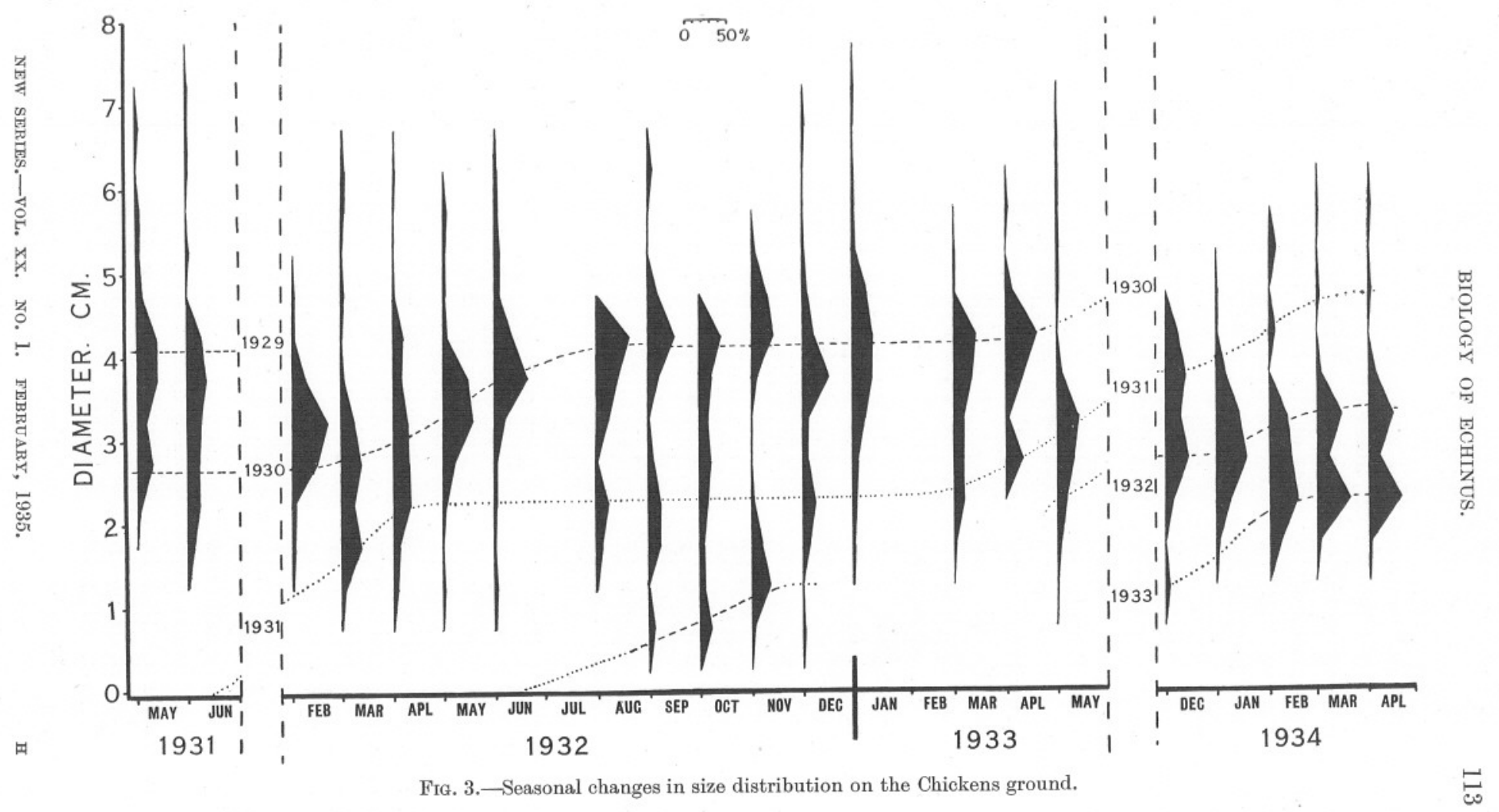


practically continuous samples from February, 1932, to May, 1933. The results are given in Table II, and as percentages in each five millimetre group for each month in Figure 3. As the groups are somewhat difficult to interpret correctly, a series of free-hand curves has been drawn to them, representing the growth of the average specimen of each year group. The growth of the 1931 brood is indicated with a more lightly dotted line as it was a bad year for urchins, and was represented in subsequent samples by too small numbers to be sharply defined. The 1932 brood, which should theoretically have settled out of the plankton about June, was first obtained in September, having presumably been too small to capture before that. In the winter months, owing to rough weather, the smaller sizes tend to wash out of the pots when these are being hauled, with the result that there is a gap in the curve for the 1932 brood between December and May, but thereafter they appear again in good numbers. The period of shell growth is very short, lasting only for about four months in the spring, after which, except in the first year urchins, there is almost complete cessation of growth for the rest of the year, as will be seen in Figure 3. The young, after metamorphosis, which takes place about June, grow continuously until their first resting period a year later. The MarchJuly growth period corresponds to a time of rising sea temperature (see Table III), ceasing before the maximum temperature is reached, and not recommencing later in the year when it drops to the same level again. The spawning period-April and May-also falls within the growing period. The gonads of the male urchin make the whole of their year's growth in this March-July period, but those of the female, at any rate on the Breakwater, continue to grow until spawning again sets in (Moore, 1934).

The size attained in the June-February non-growing phase affords a measure for the comparison of growth in different years. At this time in $1932-33$, the 1931 year group had a mean diameter of about $2 \cdot 3 \mathrm{~cm}$., while the 1930 and 1932 groups, at a corresponding age had diameters of 2.7 and $2.8 \mathrm{~cm}$. respectively. 1931 was thus a very bad year for this species, and 1930 and 1932 normal years, 1933 appears to have been a very good year judging by the numbers of surviving members of that year group in 1934, but samples were not obtained sufficiently late in that year to determine the resting size for the 1933 group. The deficiency of the 1931 group is still seen in 1933-34, when their size is $3.8 \mathrm{~cm}$., as compared with $4 \cdot 2 \mathrm{~cm}$., for the 1929 and 1930 groups at a corresponding age.

The variation in size attained by the different year groups might be accounted for either by direct variation in the available food supply during the year in question, or else by variation in time of hatching, and hence in time available for growth before the onset of winter. Probably both contribute to the observed effect. The favourability of a given year 
appears to be correlated with the sea temperature prevailing. MacBride (1914, p. 517) gives the larval life of Echinus esculentus in captivity as forty-five to sixty days, and this has been confirmed at Port Erin. Taking this figure, the larval planktonic life of the urchin will be during the period March-June. The weekly sea temperatures at Port Erin during this period had a mean deviation from the normal (obtained from the analysis of 25 years results) of $-0 \cdot 69^{\circ} \mathrm{C}$. in $1931,+0 \cdot 13^{\circ}$ in 1932 and $+0 \cdot 24^{\circ}$ in 1933 . The rate of rise of sea temperature at this period is $4 \cdot 8^{\circ} \mathrm{C}$. per hundred days, so that the above temperatures may be translated into a retardation of fourteen days in 1931, and accelerations of three and five days in 1932 and 1933 respectively. The difference in time of $50 \%$ spawning in 1931 and 1932 was in the same direction, and of the order of eleven days.* The unfavourableness of 1931 at Port Erin was reflected also in the very small spat-fall of Echinocardium cordatum, while 1932 and 1933 were good years for that species, and 1933 was also noticeable for an exceptionally heavy spat-fall of Balanus balanoides.

The size distribution data from the Breakwater are of a more complicated nature. In the first place the population on this ground is supplied entirely by migration from deeper water, and no young specimens at all are to be found on it. With the omission of at least one complete year group, the only available method of dating the several peaks found in size distribution curves from this locality is on the evidence of annual rings, as is described later. The second difficulty arises from the presence of double peaks for each expected year group. This was found in a large sample of 276 urchins in November-December, 1933, and confirmed in a further sample of 149 the following February (Table IV). In a further sample of 160 urchins in March, 1934, the sexes were therefore distinguished, and the peaks now resolved themselves into a simple series, with the females in each case slightly larger than the corresponding males, as shown below (and in Table V).

Breakwater. Year group sizes, March, 1934. Diameters in cm.

$\begin{array}{ccccccc}\hat{0} & - & 6.55 & (7 \cdot 7) & 8 \cdot 4 & - & - \\ \text { ㅇ } & 4.8 & 6.8 & 8 \cdot 0 & 8.65 & 9 \cdot 6 & 10 \cdot 6\end{array}$

The records from the earlier work on the gonads of this species provided further seasonal size distribution data in which the sex was recorded for each animal. The results for six hundred and fifty-four urchins are given in Tables VI and VII, and curves drawn from these in Figure 4. These show a summer-autumn period when there is no growth, similar to that found on the Chickens, but here the period of growth is of longer duration. The two sexes, while finally attaining the same size each year, have their period of growth at a slightly different time, and the interesting point

\footnotetext{
* See Table III for Port Erin temperature data.
} 
emerges that in the cold year 1931 it was the males which grew before the females, while in the warm years 1932 and 1933 the females grew before the males. The difference in growth period on the Breakwater and Chickens grounds probably reflects the very different conditions of food in the two localities.

\section{Annual Rings and their Evidence on Growth Rate.}

At the suggestion of Dr. A. C. Stephen, an attempt was made to find some structure in the urchin which showed bands comparable with the annual rings in many fish vertebræ, and otoliths, molluse shells, etc. The

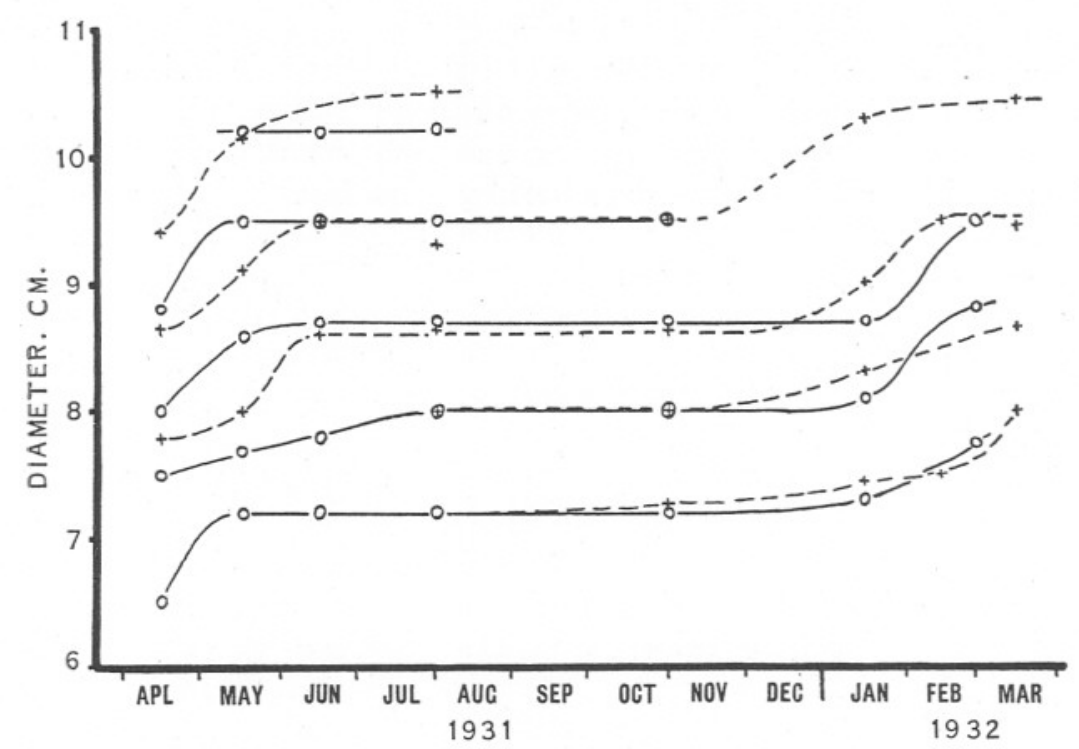

Fig. 4.-Growth of successive year groups on theBreakwater.

ô; - - - - ㅇ. .

following method, although laborious, proved the most satisfactory, but it should be noted that any of the other plates of the urchins might have been used. The apical system of the urchin was removed with scissors, and air dried. In larger specimens the genital plates were then separated and treated separately, while in urchins which were too small for this the apical system was treated whole. Each genital plate was rubbed down on fine sand paper (emery paper is unsuitable as it stains the plates) until the outer surface was removed, and the rings showing to the best advantage. This stage could only be found by practice, and varied in different individuals, but as four genital plates were available, one or more could be sacrificed in obtaining the optimum result. The plate was damped with alcohol and examined with a hand lens from time to time during the 
grinding, and when finished, it was transferred for a few minutes to absolute alcohol, and then to xylol, and finally mounted face downwards on a slide with Canada balsam. When dry the plate could then be examined through the slide. The sets of four genital plates of from four to seven urchins could be mounted on one $3^{\prime \prime} \times 1 \frac{1}{2}^{\prime \prime}$ slide.

The genital plate is five-sided, with the genital pore normally situated
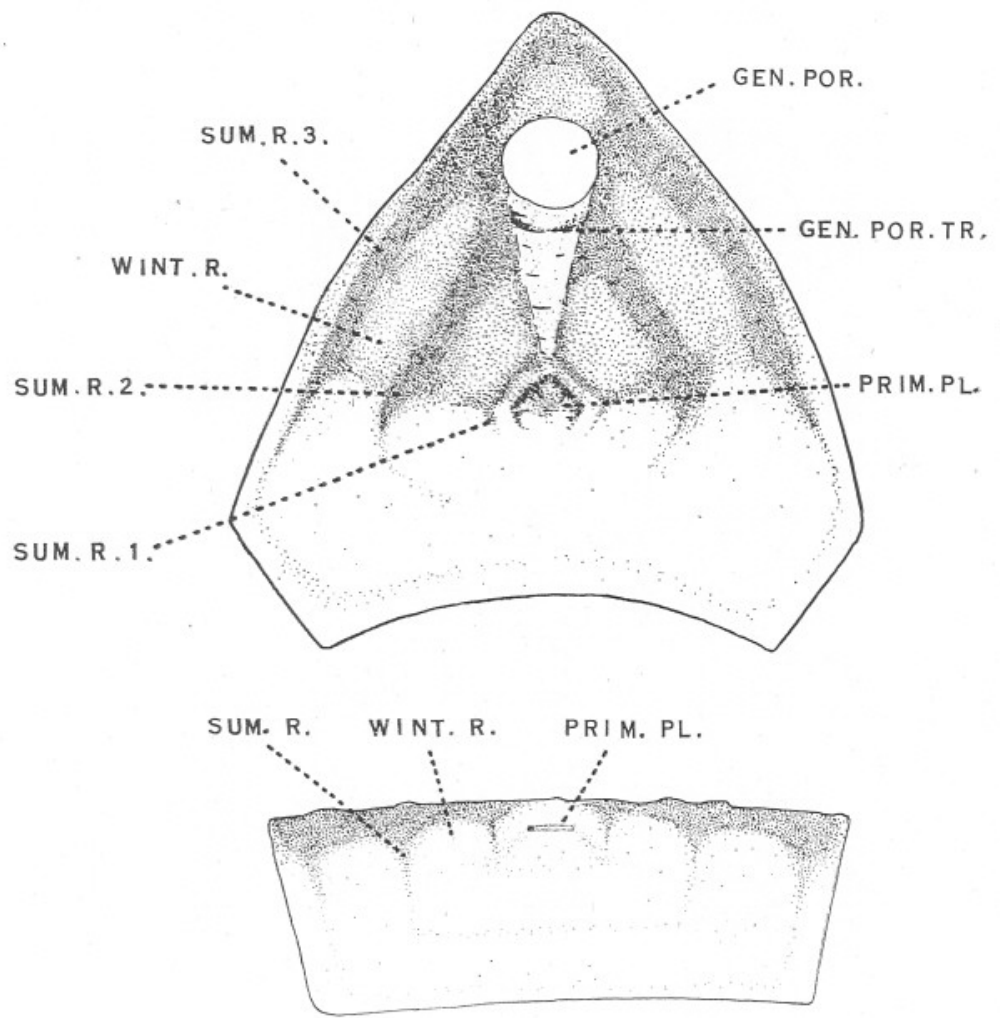

FIG. 5.-Genital plate showing three summer rings. A, horizontal section; B, vertical section. Sum. R., Summer ring. Wint. R., Winter ring. Gen. Por., Genital Pore. Gen. Por. Tr., Genital pore track. Prim. Pl., primitive, post-metamorphic plate.

at the apex (Fig. 5A). In transverse section (Fig. 5в) there is seen to be an external pigment layer which increases in depth towards the edge, and when being ground, this pigment layer is found to be considerably harder than the uncoloured layer beneath it. In the centre, and close to the surface is a thin plate which appears to be the first-formed post-larval genital plate. The depth of the pigment layer varies seasonally, giving rise to the structures referred to as annual rings. In some transverse sections these may be seen faintly indicating the successive stages of 
growth of the sides and inner surface of the plate, and showing that the addition of new material to the plate has been almost entirely on these surfaces, and hardly at all on the outside. The surface of the plate is ground away until the deeper summer pigment rings stand out clearly between regions of white. Owing to the convexity of the shell, and to the deepening of the pigment layer peripherally, it is difficult to show all the rings to the best advantage in a horizontal cut, and it was

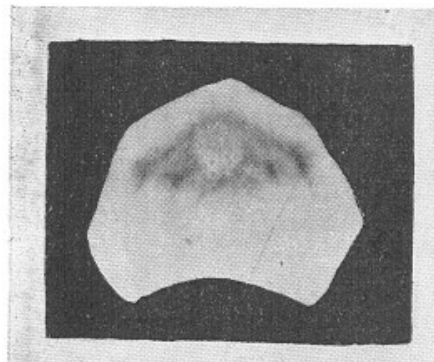

B

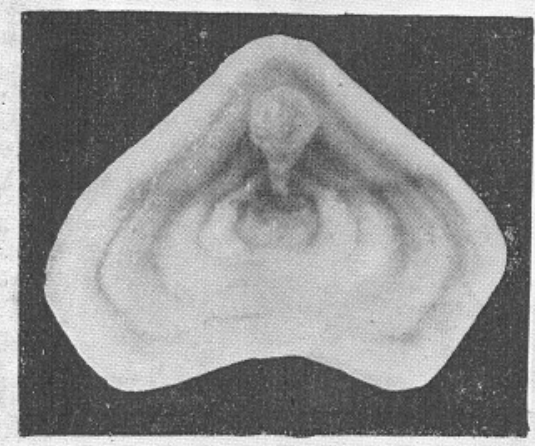

D

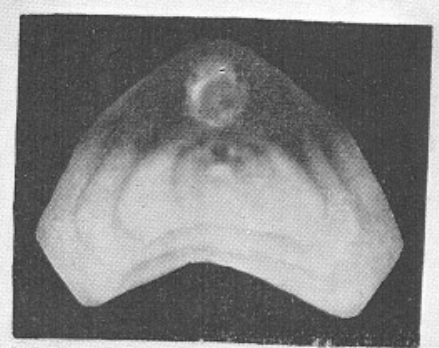

C

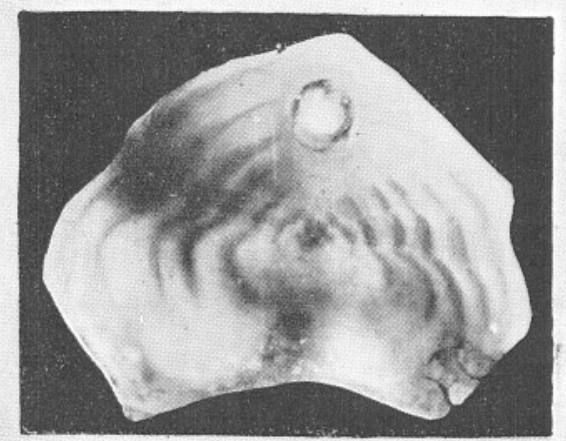

E

FIG. 6.-Horizontal sections of genital plates showing primitive plate in centre of each, and one (a), two (b), three (c), four (d) and six (e) dark winter zones outside. a. and d, Breast specimens, $\times 11$. b. and $c$. Chickens specimens, $\times 15$. e. Breakwater specimen. $\times 11$.

therefore found expedient to grind the plate more deeply at one end, thus showing each ring clearly at some point in its course (Fig. 5A). The genital pore moves outwards in the plate with increasing size, and the space behind it is filled in with calcareous deposit, frequently unpigmented, which appears as a wedge-shaped track behind it. Abnormalities of the genital pore were fairly common. Sometimes it was situated to one side of the plate, and more rarely at the wrong end. More often there were two pores in the same plate, and in one case there were three. In these cases the track left by the pore showed that it was single at metamorphosis, 
and divided later. A set of photographs of selected plates is shown in Figure 6 . The primitive plate, when visible in the section, shows as a dark region in the centre of the plate, rather similar to the first summer ring, from which it must be distinguished. Between it and the first dark ring there is usually a narrow light zone, apparently corresponding to a period immediately after metamorphosis when the little urchin is either not feeding at all, or else not taking the same pigment-providing diet that it does soon after.

The seasonal identity of these rings is established from the examination of the relative width and colour of the outermost band at different

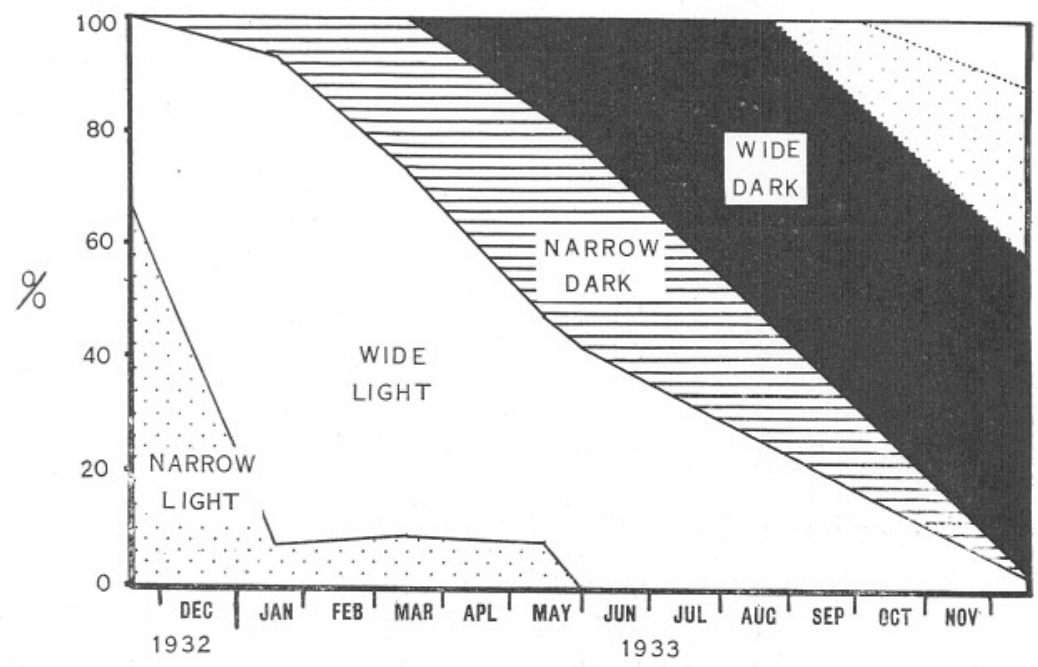

FIG. 7.-Seasonal changes in the colour of the outermost zone of the genital plates, from the Chickens.

seasons. The results obtained from a hundred and fifty-four urchins from the Chickens are shown in Figure 7. The period of new shell growth from March to July is the time of inception of a new dark summer zone in the shell, but apparently pigment can continue to be laid down in the shell by the inter-plate membranes, even when deposition of shell has ceased. This is to be expected, since newly formed calcium carbonate adsorbs pigments more readily than that which has been longer deposited. Individual variation is found, but it is not sufficient to confuse the zones of successive years, since by spring all urchins show an outer region of varying width of light shell. Similar seasonal changes were found on the Breakwater and Breast grounds.

The validity of using these rings for determining age is shown by comparison of the mean sizes for successive year groups so obtained, with the results obtained from the same material from the size distributions. In 
Figure 8 this comparison is made for the Chickens, the curves being those drawn through the peaks of the size groups in Figure 3, and the rings show the means for the annual ring sizes, and the numbers of animals from which each was obtained. The numbers available were not very large,

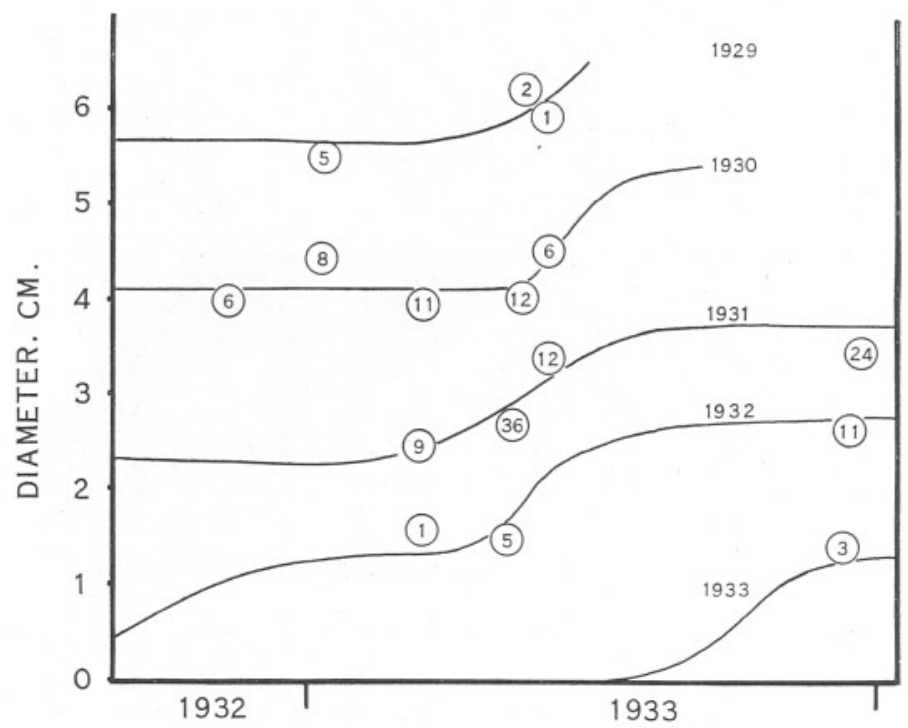

FIG. 8.-Growth of urchins from the Chickens, determined from sizedistribution data (curves), and mean year-group sizes as determined from year rings (circles). The figures in the circles indicate numbers of specimens.

but the agreement is sufficiently good to indicate the validity of the method.

A possible error is introduced in the comparatively low percentage of the urchins in which the rings were readable. In the case of the Chickens samples $79 \%$ could be determined, but on the Breakwater the percentage fell to forty-six. If the individuals which are not readable have consistently a different growth rate from those which are readable, an error will certainly be introduced, but there is no evidence to suggest this, and the goodness of fit with results obtained from size groupings make it seem unlikely. At any rate, this is the best method of age determination at present available for the urchins. Attempts were made to keep urchins alive in a large cage on the Breakwater, but without success. In addition a method of attaching a numbered tag to the urchin with an elastic band proved impracticable.

The method of annual ring counting was applied to material from the Breakwater and Breast grounds, and the resulting growth rates are shown in Figure 10. There are no available size-distribution data for the Breast, 
but for the Breakwater the results from the two methods are in substantial agreement as shown in the table below. It should be noted that the interval between the November-December and the March samples covers part of the growing period, with the result that the results for the latter

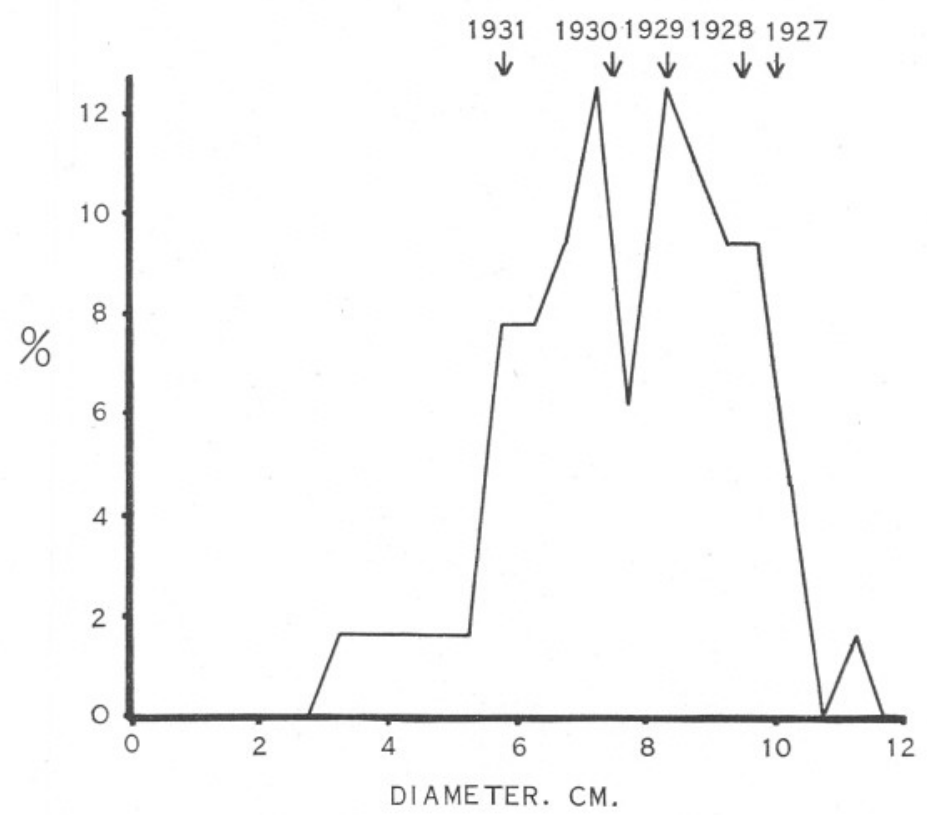

FIG. 9.-Size distribution for Keppel Pier, Millport, in February, 1934. Arrows show mean year-group sizes as indicated by year rings.

period are slightly larger than the former, especially in the case of the smallest sizes.

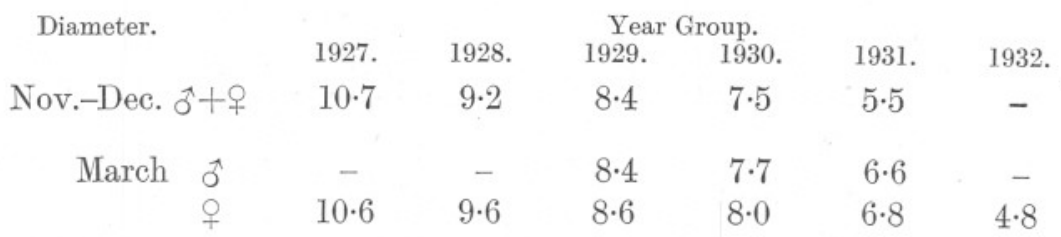

The only previous data on the growth of this species are those of Elmhirst (1922, p. 667), where the sizes of urchins for the Clyde are given at one, two, three and four years old as 4, 4-7, 7-9 and 9-11 cm. respectively. A sample of 64 urchins trawled by him off Keppel Pier in February, 1934, was examined, both for size distribution and annual rings, with the results shown in Figure $9: 51 \%$ of the urchins were readable. The mean year group sizes obtained from the annual rings are in 
good agreement with those shown in the size distribution diagram, but indicate a complete absence of the first two year groups. Elmhirst assumed that the groups he found were composed of animals of $1,2,3$ and 4 years old, and if this is the case, his results are in striking disagreement with those for Keppel. If on the other hand he was dealing with material from which the smallest sizes were missing, and he really had animals of $3,4,5$ and 6 years old, his results would approximate better to those from Keppel. Such a deficiency of small sizes might have been due either to

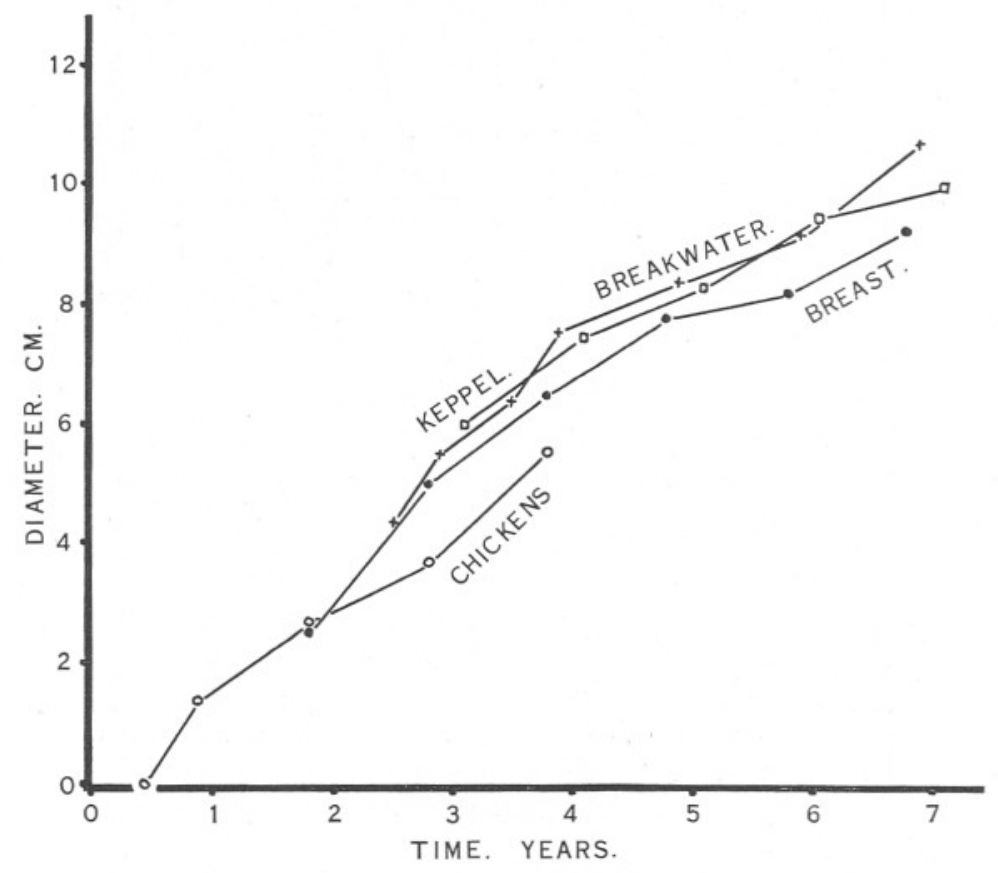

Fig. 10.-Growth of Echinus esculentus.

the selective action of the trawl with which they were taken, or to the result of previous unfavourable years.

The growths throughout life of typical urchins on the three Port Erin grounds, and at Keppel, are shown in Figure 10. In the case of the Chickens, on which seasonal observations had been made, the winter size is taken for comparison with the other grounds. As might be expected, growth is considerably slower on the Chickens ground than on any of the others; conditions there being presumably unfavourable. Growth on the Breast is more rapid, but slightly less so than on the Breakwater where, as reflected in the sizes of the gonads, there is considerably more available food than offshore. The Keppel sample shows a very similar rate to the Breakwater. 
The largest urchin obtained from the Chickens had a diameter of seven centimetres, and was therefore probably four years old, but the usual size was considerably less than this. On the Breast a few specimens were taken up to $10 \mathrm{~cm}$., but the usual limit was nine, corresponding to an age of six or seven years. The largest specimen from the Breakwater was $12 \cdot 1 \mathrm{~cm}$. in diameter, and probably seven or eight years old, although its rings were not countable. This was, however, exceptionally large, and the limit for ordinary specimens is about ten centimetres or six years. At Plymouth urchins over fifteen centimetres in diameter are taken, and it is hoped that it may be possible to determine the growth rate there also in the future.

I wish to acknowledge my indebtedness for assistance and suggestions in this work, to Prof. J. H. Orton, Dr. A. C. Stephen, Mr. R. Elmhirst and all the staff of the Port Erin and Plymouth laboratories.

\section{SUMMARY.}

1. Echinus esculentus was studied from four localities in the Isle of Man and from one in the Clyde.

2. The inshore races are thicker shelled and flatter, and on all grounds the urchins become taller with increasing age.

3. Size distribution measurements on the Chickens material showed a rapid growing period in the spring, followed by cessation of growth for the rest of the year. There is a correlation between amount of growth in a given year, and the sea temperature. On the Breakwater the males and females grow at slightly different times of year.

4. Concentric pigmented rings are demonstrated in the test, and are shown to be annual. They are used for estimating the growth rates on the different grounds, which are compared.

5. The duration of life is four to eight years, and perhaps more in the very large southern urchins. 


\section{REFERENCES.}

Bruce, J. R. 1928. Physical Factors on the Sandy Beach. Part I. Tidal, Climatic and Edaphic. Journ. Mar. Biol. Assoc., N.S., Vol. XV, No. 2, p. 535.

Elmhirst, R. E. 1922. Habits of Echinus esculentus. Nature, Nov. 18. MACBride, E. W. 1914. Text Book of Embryology. Vol. I. Invertebrata. Macmillan \& Co. London.

Moore, H. B. 1934. A Comparison of the Biology of Echinus esculentus in Different Habitats. Part I. Journ. Mar. Biol. Assoc., N.S., Vol. XIX, No. 2.

Thompson, D'Arcy W. 1917. On Growth and Form. Cambridge University Press.

\section{TABLE I.}

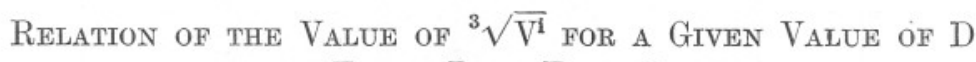
on the Three Port Erin Grounds.

\begin{tabular}{cc}
\multicolumn{2}{c}{ Breakwater. } \\
D. & $\sqrt[3]{ } \overline{V^{1}}$ \\
cm. & cm. \\
$4 \cdot 40$ & $2 \cdot 91$ \\
$4 \cdot 84$ & $3 \cdot 13$ \\
$5 \cdot 87$ & $3 \cdot 99$ \\
$7 \cdot 14$ & $4 \cdot 95$ \\
$7 \cdot 59$ & $5 \cdot 31$ \\
$8 \cdot 52$ & $5 \cdot 93$ \\
$8 \cdot 88$ & $6 \cdot 17$ \\
$9 \cdot 37$ & $6 \cdot 57$ \\
$(10 \cdot 2)$ & $(7 \cdot 15)$
\end{tabular}

Breast.

D. $\quad \sqrt[3]{ } \bar{\nabla}^{1}$

cm. cm.

$1 \cdot 31 \quad 0 \cdot 73$

$6 \cdot 70 \quad 4: 77$

$7 \cdot 22 \quad 5 \cdot 03$

$7 \cdot 37 \quad 5 \cdot 20$

$7 \cdot 79 \quad 5 \cdot 47$

$8 \cdot 41 \quad 5 \cdot 86$

$(9 \cdot 33) \quad(6 \cdot 38)$
Chickens.

$\begin{array}{cc}\begin{array}{c}\text { D. } \\ \text { cm. }\end{array} & \begin{array}{c}3 \sqrt{\bar{V}^{i}} \\ \mathrm{~cm} .\end{array} \\ 1.65 & 1 \cdot 03 \\ 2 \cdot 39 & 1 \cdot 43 \\ 3.02 & 1.99 \\ 3.52 & 2 \cdot 33 \\ 4.58 & 3.08 \\ (5.63) & (3.96)\end{array}$

Bracketed numbers are supported by six or less specimens. 
TABLE II.

Stze Distributions of "Chickens" Urchins for each Month given as Numbers in each 0.5 cm. Group (Test Diameters).

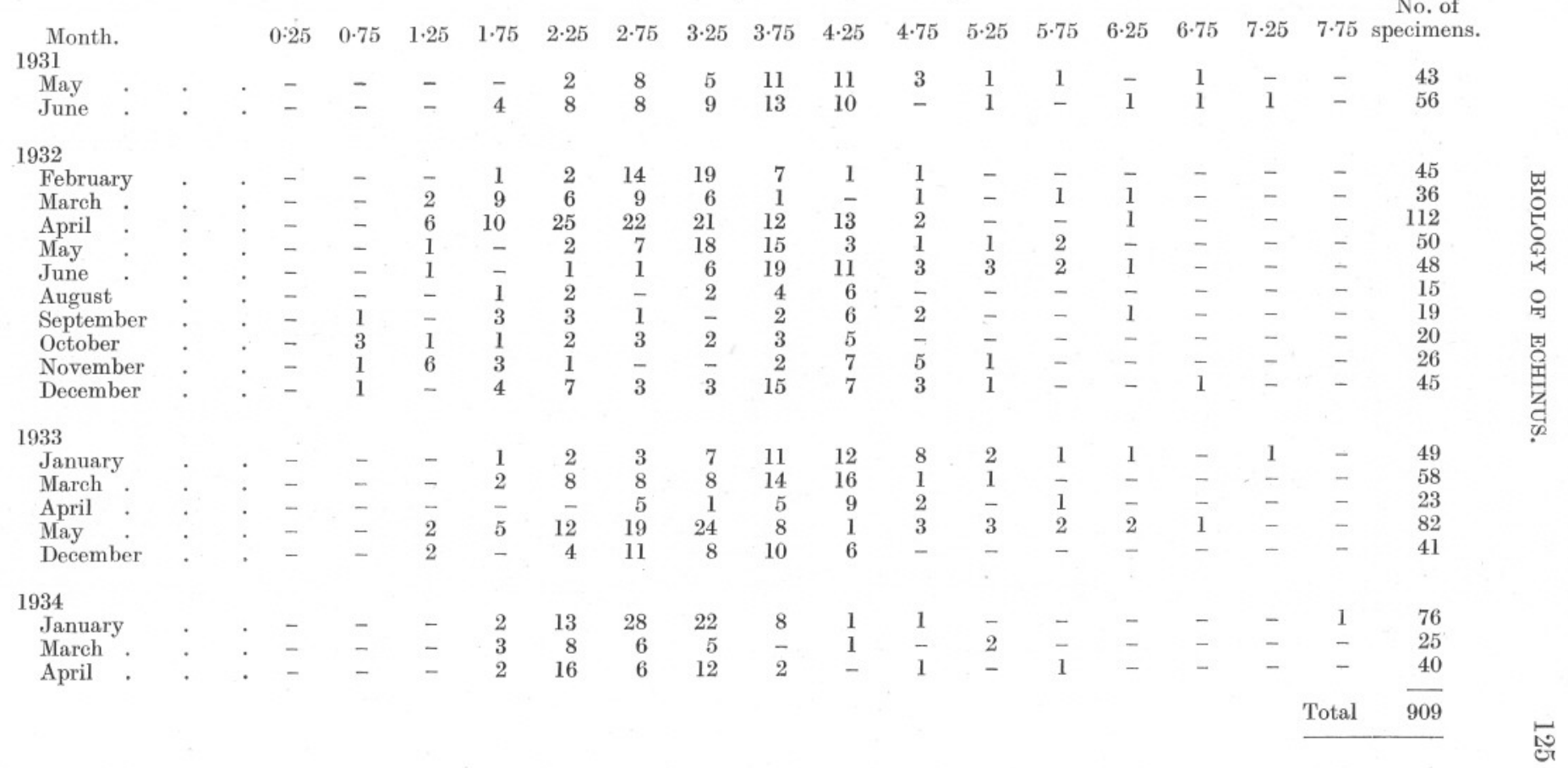




\section{TABLE III.}

Monthly Mean Temperatures for Port Erin Bay (Surface, 9 a.m.). As given by Bruce (1928), from an analysis of 25 years' results, and the variation of the monthly means from the above in the years 1930-33.

\begin{tabular}{|c|c|c|c|c|}
\hline Month. & Mean. ${ }^{\circ} \mathrm{C}$. & 1930. & 1931. & 1932. \\
\hline January & $7 \cdot 78$ & +0.8 & $+0 \cdot 3$ & $+1 \cdot 4$ \\
\hline February & $7 \cdot 08$ & $0 \cdot 0$ & 0.0 & +0.9 \\
\hline March & $6 \cdot 78$ & $+0 \cdot 1$ & -0.8 & +0.7 \\
\hline April & $7 \cdot 43$ & $0 \cdot 0$ & -0.5 & +0.6 \\
\hline May & 8.97 & $-0 \cdot 1$ & -0.5 & $+0 \cdot 1$ \\
\hline June & 10.94 & $+0 \cdot \tilde{5}$ & $-0 \cdot 1$ & $+0 \cdot 3$ \\
\hline July & $12 \cdot 77$ & $+0 \cdot 3$ & -0.4 & +0.5 \\
\hline August & $13 \cdot 76$ & $0 \cdot 0$ & $-0 \cdot 3$ & +0.6 \\
\hline September & $13 \cdot 32$ & +0.4 & $-0 \cdot 1$ & +0.6 \\
\hline October & $12 \cdot 29$ & +0.2 & -0.9 & $-0 \cdot 2$ \\
\hline November & $10 \cdot 44$ & +0.4 & $+1 \cdot 1$ & $+0 \cdot 2$ \\
\hline December & $8 \cdot 74$ & $+1 \cdot 1$ & +1.4 & +0.9 \\
\hline
\end{tabular}

TABLE IV.

Size Distribution on the Breakwater in November-December, 1933, and in February, 1934.

Expressed as percentages in two millimetre groups. November-December sample, 149 urchins; February sample, 276 urchins.

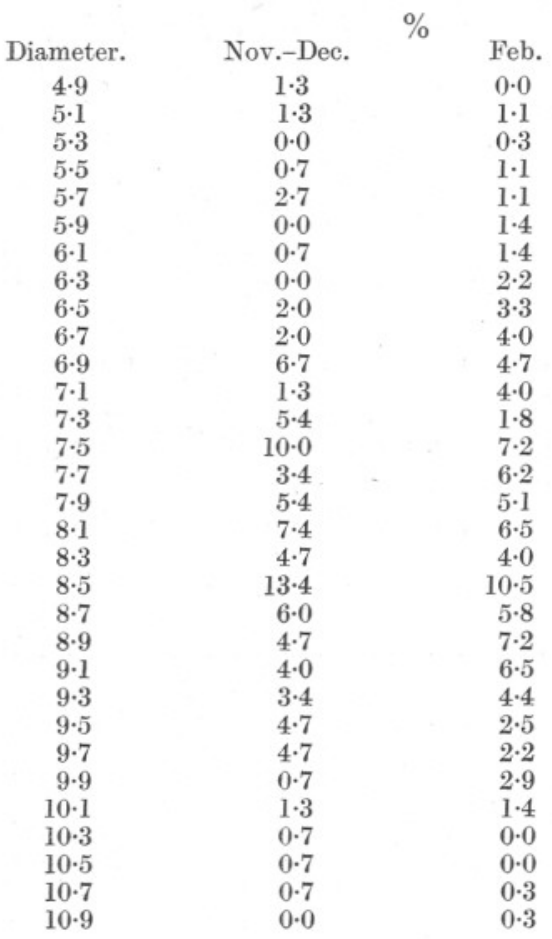




\section{TABLE V.}

Size Distribution on the Breakwater in March, 1934, Expressed as Percentages in 3 mm. Groups.

Total 85 males and 75 females.

$\begin{array}{ccc}\text { Diameter. } & \text { Males. } & \text { Females. } \\ 4 \cdot 45 & 0 \cdot 0 & 0 \cdot 0 \\ 4 \cdot 75 & 0 \cdot 0 & 2 \cdot 7 \\ 5 \cdot 05 & 0 \cdot 0 & 1 \cdot 3 \\ 5 \cdot 35 & 0 \cdot 0 & 0 \cdot 0 \\ 5 \cdot 65 & 0 \cdot 0 & 0 \cdot 0 \\ 5 \cdot 95 & 1 \cdot 2 & 1 \cdot 3 \\ 6 \cdot 25 & 2 \cdot 4 & 2 \cdot 7 \\ 6 \cdot 55 & 3 \cdot 5 & 4 \cdot 0 \\ 6 \cdot 85 & 2 \cdot 4 & 9 \cdot 3 \\ 7 \cdot 15 & 4 \cdot 7 & 0 \cdot 0 \\ 7 \cdot 45 & 8 \cdot 2 & 5 \cdot 3 \\ 7 \cdot 75 & 8 \cdot 2 & 12 \cdot 0 \\ 8 \cdot 05 & 11 \cdot 8 & 17 \cdot 3 \\ 8 \cdot 35 & 20 \cdot 0 & 8 \cdot 0 \\ 8 \cdot 65 & 16 \cdot 5 & 14 \cdot 7 \\ 8 \cdot 95 & 7 \cdot 1 & 9 \cdot 3 \\ 9 \cdot 25 & 4 \cdot 7 & 1 \cdot 3 \\ 9 \cdot 55 & 3 \cdot 5 & 5 \cdot 3 \\ 9 \cdot 85 & 2 \cdot 4 & 2 \cdot 7 \\ 10 \cdot 15 & 2 \cdot 4 & 0 \cdot 0 \\ 10 \cdot 45 & 1 \cdot 2 & 2 \cdot 7 \\ 10 \cdot 75 & 0 \cdot 0 & 2 \cdot 7 \\ 11 \cdot 05 & 1 \cdot 0 & 0 \cdot 0\end{array}$

TABLE VI.

Size Distribution of Male Breakwater Urchins, 1931-32. Expressed as percentages in $3 \mathrm{~mm}$. groups.

\begin{tabular}{|c|c|c|c|c|c|c|c|}
\hline Diameter. & April. & May. & June. & $\begin{array}{c}\text { July+ } \\
\text { Aug. }\end{array}$ & $\begin{array}{l}\text { Oct. }+ \\
\text { Nov. }\end{array}$ & Jan. & $\begin{array}{l}\text { Feb. }+ \\
\text { March. }\end{array}$ \\
\hline $\begin{array}{l}5 \cdot 65 \\
5 \cdot 95\end{array}$ & $\begin{array}{l}0 \cdot 0 \\
1 \cdot 6\end{array}$ & & & & & & \\
\hline $6 \cdot 25$ & $3 \cdot 2$ & & $0 \cdot 0$ & $0 \cdot 0$ & & & \\
\hline 6.55 & $4 \cdot 8$ & 0.0 & $2 \cdot 8$ & $4 \cdot 6$ & $0 \cdot 0$ & & 0.0 \\
\hline $6 \cdot 85$ & $4 \cdot 8$ & $1 \cdot 6$ & $2 \cdot 8$ & 0.0 & $7 \cdot 5$ & $0 \cdot 0$ & $5 \cdot 7$ \\
\hline $7 \cdot 15$ & $6 \cdot 5$ & $6 \cdot 5$ & 0.0 & $4 \cdot 6$ & $9 \cdot 5$ & $13 \cdot 3$ & $7 \cdot 1$ \\
\hline $7 \cdot 45$ & $4 \cdot 8$ & $1 \cdot 6$ & $2 \cdot 8$ & 0.0 & $11 \cdot 9$ & $16 \cdot 7$ & $7 \cdot 1$ \\
\hline $7 \cdot 75$ & $14 \cdot 5$ & $11 \cdot 3$ & $2 \cdot 8$ & 0.0 & $4 \cdot 8$ & $13 \cdot 3$ & $18 \cdot 6$ \\
\hline 8.05 & $16 \cdot 1$ & $9 \cdot 7$ & $2 \cdot 8$ & $4 \cdot 6$ & $16 \cdot 7$ & $26 \cdot 7$ & $11 \cdot 4$ \\
\hline $8 \cdot 35$ & $11 \cdot 3$ & $12 \cdot 9$ & $11 \cdot 1$ & $13 \cdot 6$ & $7 \cdot 1$ & $6 \cdot 6$ & $8 \cdot 6$ \\
\hline $8 \cdot 65$ & $11 \cdot 3$ & $17 \cdot 7$ & $16 \cdot 7$ & $18 \cdot 2$ & $14 \cdot 3$ & $10 \cdot 0$ & $11 \cdot 4$ \\
\hline 8.95 & $9 \cdot 7$ & $9 \cdot 7$ & $11 \cdot 1$ & $9 \cdot 1$ & $9 \cdot 5$ & $6 \cdot 6$ & $7 \cdot 1$ \\
\hline $9 \cdot 25$ & $6 \cdot 5$ & $4 \cdot 8$ & 0.0 & $4 \cdot 6$ & $7 \cdot 1$ & $3 \cdot 3$ & $8 \cdot 6$ \\
\hline $9 \cdot 55$ & $3 \cdot 2$ & $8 \cdot 1$ & $19 \cdot 4$ & $9 \cdot 1$ & $9 \cdot 5$ & 0.0 & $1 \cdot 4$ \\
\hline $9 \cdot 85$ & 0.0 & $4 \cdot 8$ & $5 \cdot 6$ & $13 \cdot 6$ & 0.0 & 0.0 & $0 \cdot 0$ \\
\hline $10 \cdot 15$ & $1 \cdot 6$ & $6 \cdot 5$ & 13.9 & $4 \cdot 6$ & $2 \cdot 4$ & $3 \cdot 3$ & $1 \cdot 4$ \\
\hline $10 \cdot 45$ & 0.0 & $1 \cdot 6$ & $5 \cdot 6$ & $9 \cdot 1$ & 0.0 & 0.0 & $0 \cdot 0$ \\
\hline $10 \cdot 75$ & & $0 \cdot 0$ & $2 \cdot 8$ & $4 \cdot 6$ & & & \\
\hline $11 \cdot 05$ & & $3 \cdot 2$ & 0.0 & 0.0 & & & \\
\hline $11 \cdot 35$ & & 0.0 & & & & & \\
\hline o. of urchins & 62 & 62 & 36 & 22 & 42 & 30 & 70 \\
\hline
\end{tabular}


TABLE VI.

- Size Distribution of Female Breakwater Urchins, 1931-32. Expressed as percentages in $3 \mathrm{~mm}$. groups.

\begin{tabular}{|c|c|c|c|c|c|c|c|}
\hline $\begin{array}{c}\text { Diameter. } \\
\mathbf{5 \cdot 6 5}\end{array}$ & $\begin{array}{c}\text { April+ } \\
\text { May. } \\
0.0\end{array}$ & June. & $\begin{array}{l}\text { July+ } \\
\text { Aug. }\end{array}$ & $\begin{array}{l}\text { Oct. }+ \\
\text { Nov. }\end{array}$ & Jan. & Feb. & March. \\
\hline $\begin{array}{l}5 \cdot 65 \\
5 \cdot 95\end{array}$ & $\begin{array}{l}0 \cdot 0 \\
1 \cdot 3\end{array}$ & & & & & & \\
\hline $6 \cdot 25$ & $4 \cdot 0$ & & & & & & \\
\hline $6 \cdot 55$ & $0 \cdot 0$ & & & $0 \cdot 0$ & $0 \cdot 0$ & & $0 \cdot 0$ \\
\hline $6 \cdot 85$ & $4 \cdot 0$ & & $0 \cdot 0$ & $2 \cdot 3$ & $5 \cdot 0$ & & $2 \cdot 9$ \\
\hline $7 \cdot 15$ & $2 \cdot 7$ & 0.0 & $1 \cdot 2$ & $9 \cdot 3$ & 0.0 & 0.0 & $11 \cdot 8$ \\
\hline $7 \cdot 45$ & $5 \cdot 3$ & $1 \cdot 6$ & $3 \cdot 5$ & $9 \cdot 3$ & $15 \cdot 0$ & $20 \cdot 8$ & $8 \cdot 8$ \\
\hline $7 \cdot 75$ & $10 \cdot 8$ & 0.0 & $5 \cdot 9$ & $11 \cdot 6$ & $10 \cdot 0$ & $20 \cdot 8$ & $11 \cdot 8$ \\
\hline $8 \cdot 05$ & $13 \cdot 3$ & $3 \cdot 3$ & $9 \cdot 4$ & $14 \cdot 0$ & $10 \cdot 0$ & $8 \cdot 3$ & $14 \cdot 7$ \\
\hline $8 \cdot 35$ & $5 \cdot 3$ & $6 \cdot 6$ & $9 \cdot 4$ & $4 \cdot 7$ & $30 \cdot 0$ & $12 \cdot 5$ & $2 \cdot 9$ \\
\hline $8 \cdot 65$ & $12 \cdot 0$ & $23 \cdot 0$ & $16 \cdot 9$ & $30 \cdot 2$ & $0 \cdot 0$ & $8 \cdot 3$ & $11 \cdot 8$ \\
\hline $8 \cdot 95$ & $8 \cdot 0$ & $6 \cdot 6$ & $10 \cdot 6$ & $11 \cdot 6$ & $15 \cdot 0$ & $8 \cdot 3$ & $5 \cdot 9$ \\
\hline $9 \cdot 25$ & $8 \cdot 0$ & $8 \cdot 2$ & $15 \cdot 3$ & $2 \cdot 3$ & $5 \cdot 0$ & $4 \cdot 2$ & $11 \cdot 8$ \\
\hline $9 \cdot 55$ & $4 \cdot 0$ & $21 \cdot 3$ & $11 \cdot 8$ & $4 \cdot 7$ & $0 \cdot 0$ & $12 \cdot 5$ & $11 \cdot 8$ \\
\hline $9 \cdot 85$ & $2 \cdot 7$ & $8 \cdot 2$ & $5 \cdot 9$ & 0.0 & $0 \cdot 0$ & $4 \cdot 2$ & $2 \cdot 9$ \\
\hline $10 \cdot 15$ & $10 \cdot 8$ & $8 \cdot 2$ & $2 \cdot 4$ & & $5 \cdot 0$ & 0.0 & 0.0 \\
\hline $10 \cdot 45$ & $2 \cdot 7$ & $4 \cdot 9$ & $4 \cdot 7$ & & $5 \cdot 0$ & & $2 \cdot 9$ \\
\hline $10 \cdot 75$ & $1 \cdot 3$ & $3 \cdot 3$ & $1 \cdot 2$ & & 0.0 & & 0.0 \\
\hline $11 \cdot 05$ & $4 \cdot 0$ & $1 \cdot 6$ & $1 \cdot 2$ & & & & \\
\hline $11 \cdot 35$ & $0 \cdot 0$ & 0.0 & $0 \cdot 0$ & & & & \\
\hline $11 \cdot 65$ & & $3 \cdot 3$ & $1 \cdot 2$ & & & & \\
\hline of urchins & 75 & 61 & 85 & 43 & 20 & 24 & 24 \\
\hline
\end{tabular}

